Supporting Information

\title{
Simultaneous Concentration and Separation of Enantiomers with Chiral Temperature Gradient Focusing
}

Karin M. Balss, Wyatt N. Vreeland, Karen W. Phinney, and David Ross

National Institute of Standards and Technology

This Supporting Information file contains captions for two digital movie clips.

\section{Movie M1}

Video sequence of chiral TGF of dansyl-DL-glutamic acid (corresponding to Figs. 2-3).

Step 1: Focus without CD (movie at 100x real time). The input sample $(1 \mu \mathrm{mol} / \mathrm{L}$ dansyl-D-glu, $1 \mu \mathrm{mol} / \mathrm{L}$ dansyl-L-glu in $1 \mathrm{~mol} / \mathrm{L}$ Tris-borate) was initially focused without chiral selector for about $30 \mathrm{~min}$ to a peak concentration of $1.2 \mathrm{mmol} / \mathrm{L}$ (See Supplementary Fig. 1). The focusing conditions were $\mathrm{T}_{1}=13{ }^{\circ} \mathrm{C}$ (left side in image), $\mathrm{T}_{2}=40^{\circ} \mathrm{C},+1000 \mathrm{~V} / \mathrm{cm}$.

Step 2: Introduce $\boldsymbol{\gamma}$-CD (movie in real time). The sample solution was then replaced with a solution of $10 \mathrm{mmol} / \mathrm{L} \gamma$-cyclodextrin $(\gamma-\mathrm{CD})$ in $1 \mathrm{~mol} / \mathrm{L}$ Tris-borate and the high voltage and controlled pressure were turned back on (The point in the movie when the $\gamma$-CD entered the gradient zone (time $=35 \mathrm{~s}$ ) is clearly visible as a sharp increase in intensity, a change of the emission color from orange to yellow, and an abrupt shift of the peak position towards the left.

\section{Movie M2}

Real time video sequence of chiral TGF of CBQCA-labeled R(+)- and S(-)-baclofen. The input sample (48 $\mu \mathrm{mol} / \mathrm{L}$ CBQCA-R(+)-baclofen, $21 \mu \mathrm{mol} / \mathrm{L}$ CBQCA-S(-)-baclofen in 1 $\mathrm{mol} / \mathrm{L}$ Tris-borate) was initially focused without chiral selector (not shown). The focusing conditions were $\mathrm{T}_{1}=10.5^{\circ} \mathrm{C}$ (left side in image), $\mathrm{T}_{2}=40^{\circ} \mathrm{C},+1000 \mathrm{~V} / \mathrm{cm}$. The sample solution was then replaced with a solution of $10 \mathrm{mmol} / \mathrm{L} \alpha$-cyclodextrin $(\alpha-\mathrm{CD})$ in $1 \mathrm{~mol} / \mathrm{L}$ Tris-borate and the high voltage and controlled pressure were turned back on. In this case, the interaction with the chiral selector has no effect on the emission properties of the fluorescent label so that the point in the movie when the $\alpha$-CD entered the gradient zone (time $=5 \mathrm{~s}$ ) is only indicated by a shift of the peak position towards the left. 